\title{
Mathematical Modelling Stress Distribution in a Metallic Plate with an Asymmetrical Notch
}

\author{
Sergey Konovalov ${ }^{1, a^{*}}$, Irina Komissarova ${ }^{1, \mathrm{~b}}$, Dmitry $\operatorname{Kosinov}^{1, \mathrm{c}}$, Xizhang Chen $^{2, \mathrm{~d}}$, Victor \\ Gromov ${ }^{1, \mathrm{e}}$ \\ ${ }^{1}$ Siberian state industrial university, 42, Kirov Str., 654007, Novokuznetsk, Russia \\ ${ }^{2}$ School of Mechanical and Electrical Engineering, Wenzhou University, Wenzhou 325035, China

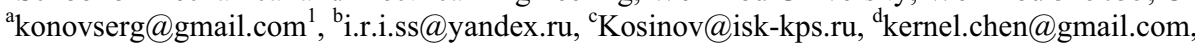 \\ 'gromov@physics.sibsiu.ru
}

\begin{abstract}
The paper is focused on analyzing $\sigma_{\mathrm{x}}, \sigma_{\mathrm{y}}, \tau_{\mathrm{xy}}$, arising in a steel plate with stress raisers when alternate bend fatigue. The research based on the finite-element method is carried out by software ANSYS. Stress distribution is studied in two planes.
\end{abstract}

\section{Introduction}

A sample stressed in a cantilevered manner was used for the purpose of research into high- and low-cycle fatigue of various structural steel classes [1-4]. Stress values around the notch-shaped stress raiser were calculated according to elasticity theory, methods of which are characterized by certain inaccuracy.

Numerous works have been addressed to the behavior of materials with various stress raisers. However, investigation into the behavior of materials with asymmetrical stress concentrators is a complex issue, which is to be solved according to the theory of strength of materials. A lot of software has been developed recently to solve mechanics problems of strength of materials, making the matters at issue more simplified.

\section{Problem statement and analysis of results}

This work is focused on mathematical modelling stress distribution in a metallic plate with an asymmetrical notch. For this purpose stress distribution in a steel plate with asymmetrical semi-cylindrical notch is analyzed. An assumption is made that a plate body is subject to alternate bending. The data were analyzed by software CAE ANSYS on the base of finite-element method [5 - 8].

A model of the sample was given in a two-dimensional view to simplify the calculation (Fig.1). The problem was solved on assumption of plate elasticity, with one its end fastened, while the other end is subject to the vertically acting force of $1000 \mathrm{~N}$.

* Corresponding author: konovserg@gmail.com 
As the defects are accumulated most intensively around the stress raisers the values $\sigma x$, $\sigma y, \tau x y$ were analyzed at distances $\pm 10 \mathrm{~mm}$ from the stress raiser in the X-direction and in the minimal section of the sample in the Y-direction (Fig.1).

The results of calculation by the software ANSYS are given below, the finite element scheme is assigned according to notch shape and dimensions.

The values $\sigma_{\mathrm{x}}$ on the sample surface (Fig.2a) vary parabolically, moreover, the minimal value $-1175 \mathrm{MPa}$ is registered in the center of the stress raiser, rising to - $200 \mathrm{MPa}$ symmetrically with respect to the distance from the centre. The values $\sigma_{\mathrm{x}}$ in the center are $390 \mathrm{MPa}$ at a distance of $1.5 \mathrm{~mm}$ (Figure $2 \mathrm{~b}$ ) from the surface. Therefore, the values increase on the whole parabola, it is not symmetrical though: for $\mathrm{x}=-10 \mathrm{~mm} \sigma_{\mathrm{x}}=-225 \mathrm{MPa}$, whereas at a distance of $+10 \mathrm{~mm} \sigma_{\mathrm{x}}=-100 \mathrm{MPa}$. At a distance of $2.4 \mathrm{~mm}$ from the surface (Fig.2c) the values $\sigma_{\mathrm{x}}$ have an opposite sign. At the same time $\sigma_{\mathrm{x}}$ in the stress raiser center equals $200 \mathrm{MPa}$, $\sigma_{\mathrm{x}}$ is $-125 \mathrm{MPa}$ for $\mathrm{x}=-10 \mathrm{~mm}$, and $-10 \mathrm{MPa}$ for $\mathrm{x}=+10 \mathrm{~mm}$, respectively. At a distance 3.1 $\mathrm{mm}$ (Figure $2 \mathrm{~d}$ ) the values $\sigma_{\mathrm{x}}$ for $\mathrm{x}=+10 \mathrm{~mm}$ and $\mathrm{x}=-10 \mathrm{~mm}$ are quite the same. However, the increase up to $\sigma_{\mathrm{x}}=610 \mathrm{MPa}$ is registered in the stress raiser center. The stresses on the sample surface in the minimal section of the stress raiser (Fig.2a and 2e) have a quite similar modulus, but their nature becomes different: tension stresses transform into compression ones.

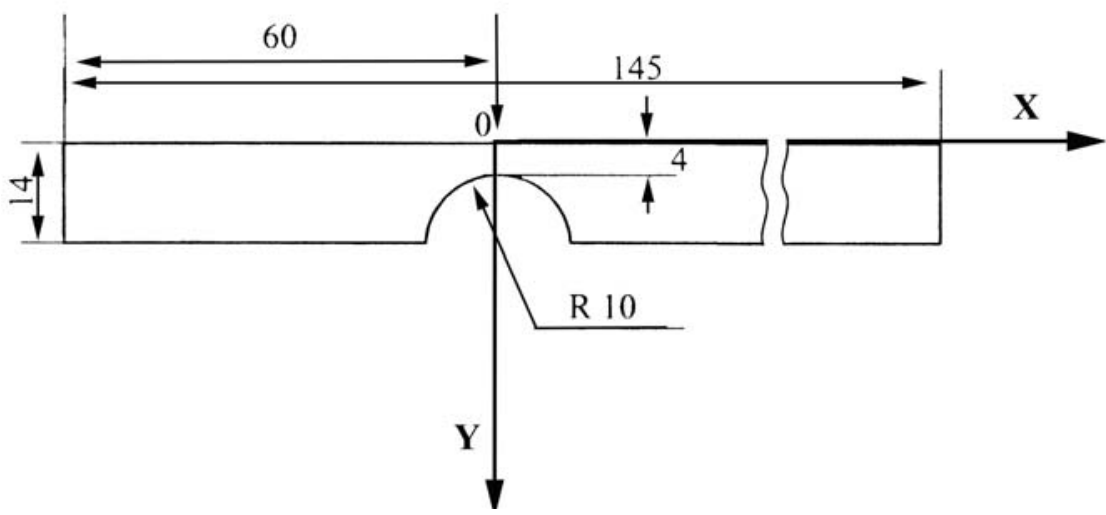

Fig.1. Plate geometry in Cartesian coordinate system

Focusing on the varying values $\sigma_{\mathrm{y}}$ an emphasis is to be laid on proximity of the plot given in Fig. 2 a, since the values $\sigma_{\mathrm{y}}$ are zero on the surface due to the dispersion of values when calculating CAE ANSYS.

Analyzing the distribution $\sigma_{\mathrm{y}}$ at a distance of $1.5 \mathrm{~mm}$ from the surface (Fig. $3 \mathrm{~b}$ ) a parabolic distribution is detected with the maximum in the center $\left(\sigma_{\mathrm{y}}=38 \mathrm{MPa}\right)$ and minimums at the extremities of intervals under consideration $\left(\sigma_{\mathrm{y}}=-10 \mathrm{MPa}\right)$. 


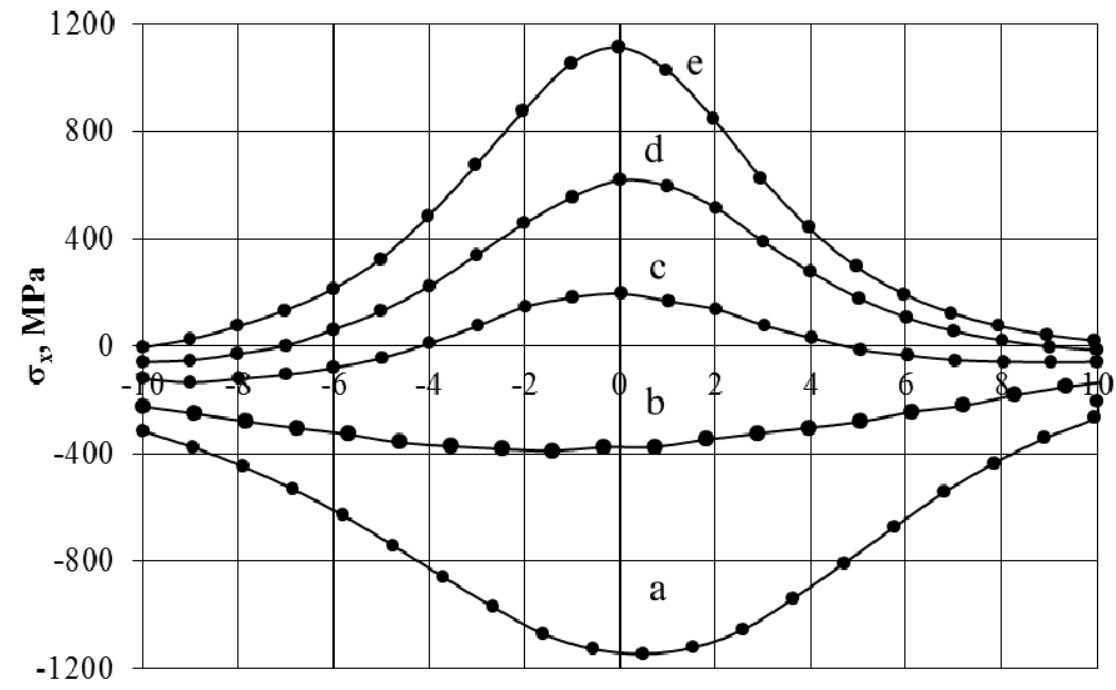

$\mathbf{X}, \mathbf{m m}$

Fig.2. Stress distribution $\sigma_{\mathrm{x}}$ in the plate. Sections at the distances from the surface: a) on the surface, $b$ ) $1.5 \mathrm{~mm}, \mathrm{c}) 2.4 \mathrm{~mm}$, d) $3.1 \mathrm{~mm}$, e) $4 \mathrm{~mm}$.

The distribution $\sigma_{\mathrm{y}}$ is nearly the same at a distance of $2.4 \mathrm{~mm}$ from the surface (Fig.3c), the maximum increases up to $60 \mathrm{MPa}$ and the minimum decreases to $-20 \mathrm{MPa}$. It is similar for the distance of $3.1 \mathrm{~mm}:-73 \mathrm{MPa}$ and $28 \mathrm{MPa}$, respectively (Fig. $3 \mathrm{~d}$ ).

Strong changes are detected at a distance of $4 \mathrm{~mm}$ (Fig.3e). Two maximums are apparent around the stress raiser at distances of $x=-3 \mathrm{~mm}$ and $\mathrm{x}=3 \mathrm{~mm}$, equaling $80 \mathrm{MPa}$ and $42 \mathrm{MPa}$, respectively. In the center of a stress raiser there is a minimum with the value $21 \mathrm{MPa}$. A probable cause of it is the surficial position of the curve to be analvzed in this area.

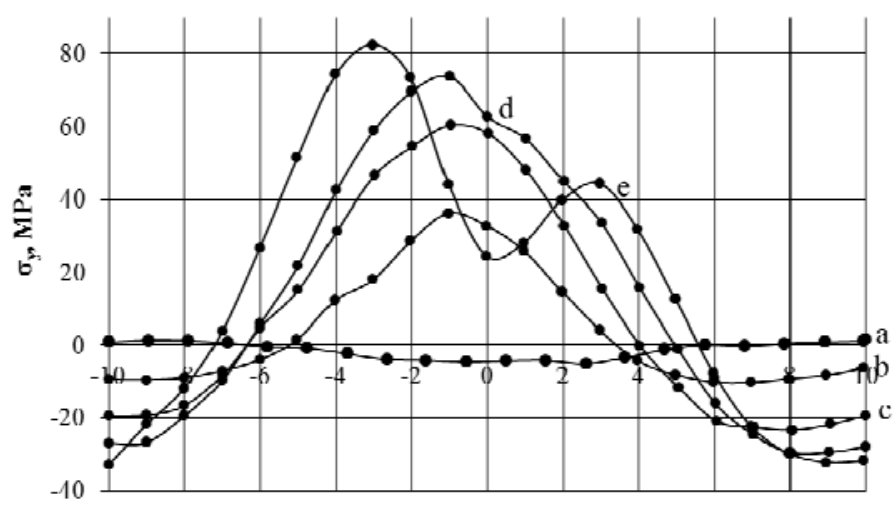

$\mathbf{X}, \mathbf{m m}$

Fig.3. Stress distribution $\sigma_{y}$ in the plate. Sections at the distances from the surface: a) on the surface, b) $1.5 \mathrm{~mm}, \mathrm{c}) 2.4 \mathrm{~mm}$, d) $3.1 \mathrm{~mm}$, e) $4 \mathrm{~mm}$.

The distribution of tangential stresses $\tau_{\mathrm{xy}}$ seems to be more interesting (Fig.4). The values $\tau_{\mathrm{xy}}$ approximate to zero on the surface at the distances $\mathrm{x}=-10 \mathrm{~mm}$, in the center and for $\mathrm{x}=10$ $\mathrm{mm}$ (Fig.4a). The minimum is detected at a distance $\mathrm{x}=-3 \mathrm{~mm}\left(\tau_{\mathrm{xy}}=-20 \mathrm{MPa}\right)$, and the 
maximum $18 \mathrm{MPa}$ is located symmetrically with the center at a distance $\mathrm{x}=4 \mathrm{~mm}$. At a distance of $1.5 \mathrm{~mm}$ from the surface (Figure $4 \mathrm{~b}$ ) the distribution $\tau_{\mathrm{xy}}$ differs in numerical values only. In the stress raiser center the values are in the range of zero, being $3 \mathrm{MPa}$. However, at a distance of $2.4 \mathrm{~mm}$ deep into the surface (Fig.4c) the plot is displaced $\tau_{\mathrm{xy}}(\mathrm{X})$ because the value in the concentrator center $\tau_{\mathrm{xy}}=50 \mathrm{MPa}$, and the $\tau_{\mathrm{xy}}$ plot $-\mathrm{X}$ - axis cross point is displaced too. Positions and values of the maximums and minimums are not displaced significantly (Fig.4c).

The second highly pronounced maximum 50MPa is registered for $\mathrm{x}=-1 \mathrm{~mm}$ at a distance $3.1 \mathrm{~mm}$ from the surface (Fig.3d). The maxi-mum, which was seen previously in Fig.4c, is displaced to $x=7 \mathrm{~mm}\left(\tau_{\mathrm{xy}}=78 \mathrm{MPa}\right)$. At a distance of $2 \mathrm{~mm}$ from the center is the minimum $\left(\tau_{\mathrm{xy}}=18 \mathrm{MPa}\right)$ registered.

At a distance $4 \mathrm{~mm}$ from the surface (Fig.3e) specifics of tangential stress distribution is similar to that registered when considering $\sigma_{\mathrm{x}}$ and $\sigma_{\mathrm{y}}$. In this case negative area of the plot is almost mirrored relative to the axis X (Fig.3c), but the maximum on the plot is $150 \mathrm{MPa}$, corresponding to $X=-2 \mathrm{~mm}$, whereas the minimum is $-95 \mathrm{MPa}$ for $\mathrm{x}=+2 \mathrm{~mm}$.

This paper provides consideration of stress distribution over the minimal section of the sample (Fig.4), since there the maximal stresses are registered.

The $\sigma_{\mathrm{x}}$ versus $\mathrm{Y}$ curve is a linear one (Fig.5a) and expressed by the interpolation equation $\sigma_{\mathrm{x}}=592 \mathrm{Y}-1188$, where $\mathrm{Y}$ is given in millimeters, and $\sigma_{\mathrm{x}}$ in MPa. The $\sigma_{\mathrm{y}}$ and $\sigma_{\mathrm{xy}}$ versus $\mathrm{Y}$ dependences (Fig. $5 \mathrm{~b}$ and $5 \mathrm{c}$ ) are of the same type with maximums in the range $2.5-3 \mathrm{~mm}$. For instance, the maximal value $\sigma_{\mathrm{y}}$ equals $60 \mathrm{MPa}$ and $\tau_{\mathrm{xy}}$ is $49 \mathrm{MPa}$, respectively.

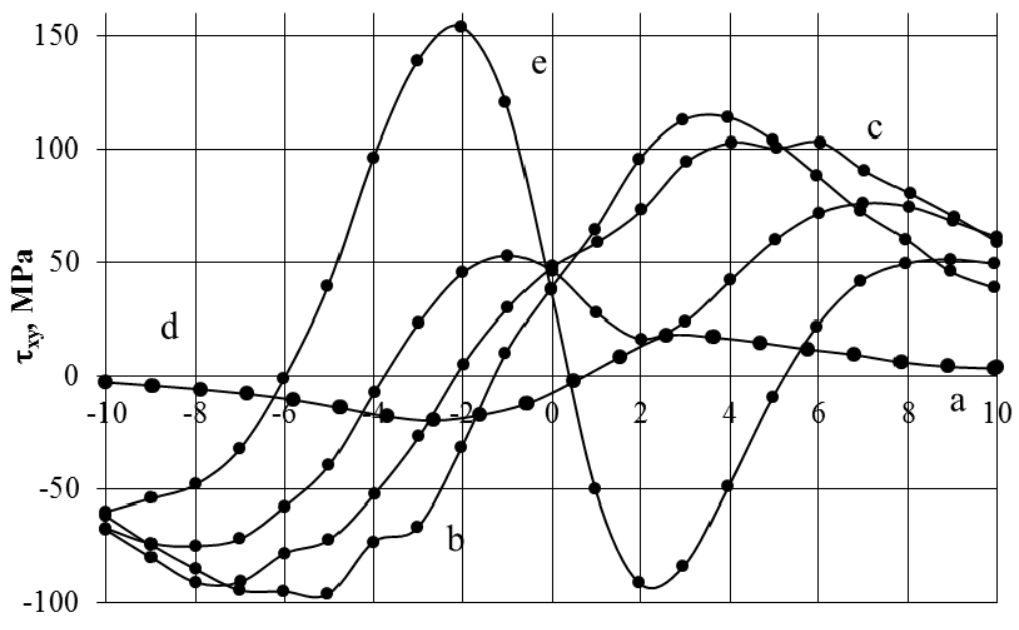

$\mathbf{X}, \mathbf{m m}$

Fig.4. Stress distribution $\tau_{\mathrm{xy}}$ in the plat. Sections at distances from the surface: a) on the surface, b) 1.5 $\mathrm{mm}$, c) $2.4 \mathrm{~mm}$, d) $3.1 \mathrm{~mm}$, e) $4 \mathrm{~mm}$. 


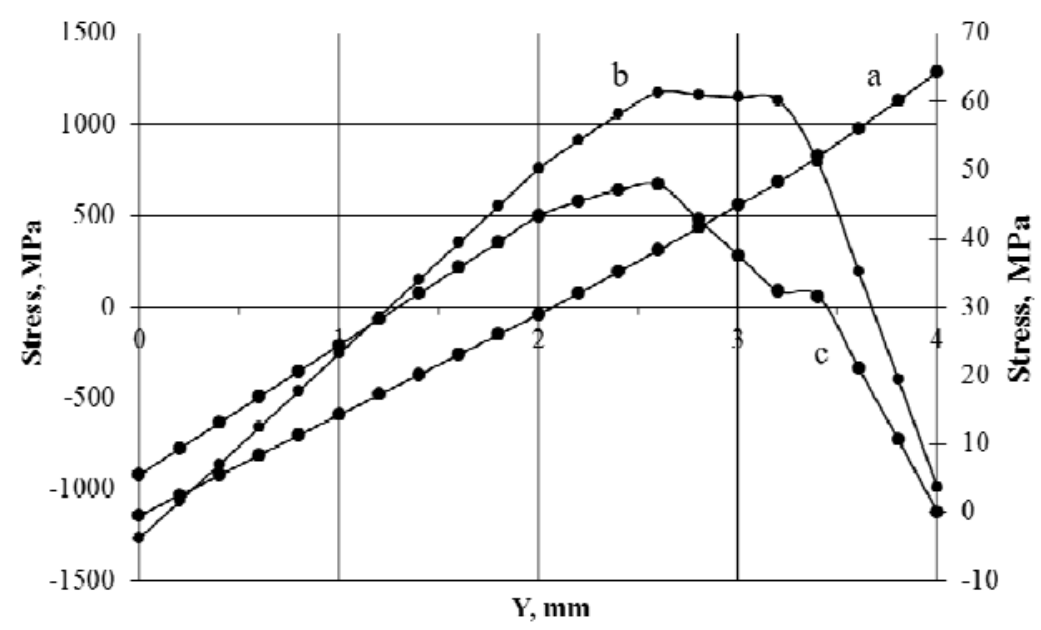

Fig.5. Stress distribution $\sigma_{\mathrm{x}}(\mathrm{a}), \sigma_{\mathrm{y}}(\mathrm{b})$, and $\tau_{\mathrm{xy}}(\mathrm{c})$ in the plate. The curves $\mathrm{b}$ and $\mathrm{c}$ are in the right ordinate of the plot.

\section{Conclusions}

To sum up, a computer model of stress distribution in a sample with asymmetrical notch makes it obvious that notch displacement is the cause of inflection points and even double peaks on stress distribution curves. Therefore, various rupture points are possible when cyclic stressing.

\section{Acknowledgement}

The work was financially supported by RFBI (project No 16-32-60048_mol_a_dk), RF President grant for state support of young Russian scientists - doctors of sciences (project No MD 2920.2015.8) and State task No 3.1496.2014/K.

\section{References}

1. V.E. Gromov, Yu.F. Ivanov, S.V. Vorobiev, S.V. Konovalov, Fatigue of steels modified by high intensity electron beams, Cambridge International Science Publishing Ltd, Cambridge, 2015.

2. V.A. Grishunin, V.E. Gromov, Yu.F. Ivanov, A.D. Teresov, S.V. Konovalov, Evolution of the phase composition and defect substructure of rail steel subjected to high-intensity electron-beam treatment, J. of Surf. Investigation. X-ray, Synchrotron and Neutron Techniques. 7 (2013) 990-995.

3. Y.F. Ivanov, K.V. Alsaraeva, E.A. Petrikova, A.D. Teresov, V.E. Gromov, S.V. Konovalov, Fractography of the fatigue fracture surface of silumin irradiated by high-intensity pulsed electron beam, IOP Conference Series: Materials Science and Engineering, 81 (2015) 12011.

4. V.E. Gromov, S.V. Gorbunov, Y.F. Ivanov, S.V. Vorobiev, S.V. Konovalov, Formation of surface gradient structural-phase states under electron-beam treatment of stainless steel, J. of Surf. Investigation 5 (2011) 974-978. 
5. N. Moës, J. Dolbow, T. Belytschko, A finite element method for crack growth without remeshing, International Journal for Numerical Methods in Engineering. 46 (1999) 131-150.

6. C. Farhat, F.X. Roux, Method of finite element tearing and interconnecting and its parallel solution algorithm, International J. for Numerical Methods in Eng. 32 (1991) 1205-1227.

7. W. Li, Z. Wen, L. Wu, X. Jin. Thermo-elasto-plastic finite element analysis of rail during wheel sliding, J. of Mechanical Eng. 46 (2010) 95-101.

8. G.R. Liu, S.S. Quek, Finite Element Method: A Practical Course, Elsevier Ltd, 2003. 